\title{
Aging Properties and Biodegradation Rate of Styrofoam Composite Filled with Modified Sawdust
}

\author{
Halimatuddahliana Nasution* and Hamidah Harahap \\ Department of Chemical Engineering, Faculty of Engineering, \\ Universitas Sumatera Utara, 20356 Medan, Indonesia \\ "Corresponding author: h_dahliana@yahoo.com
}

Published online: 31 December 2019

To cite this article: Halimatuddahliana Nasution and Hamidah Harahap (2019). Aging properties and biodegradation rate of styrofoam composite filled with modified sawdust. Journal of Engineering Science, 15(2), 17-29, https://doi.org/10.21315/ jes2019.15.2.2.

To link to this article: https://doi.org/10.21315/jes2019.15.2.2

\begin{abstract}
Aging treatment has been done to test the thermal resistance of styrofoam composite filled with modified sawdust. The results showed that the mechanical properties of the composites declined after the aging treatment was done. The percentage of retention as tensile strength, flexural strength, and impact strength were $70.0 \%, 44.3 \%$, and $41.7 \%$, respectively. These showed that the composite had encountered thermal degradation during aging treatment. For the biodegradation, the percentage of weight loss of the composites was low. The biodegradation process by hanging the composite in open air was relatively faster than burying in soil. These results, which were confirmed by scanning electron microscopy, showed that the composites have some pores/cavities.
\end{abstract}

Keywords: composite, styrofoam, sawdust, aging treatment, biodegradation

\section{INTRODUCTION}

\subsection{Composite}

Composite material derived from a mixture of styrofoam and sawdust is one of the alternatives in the utilisation of styrofoam waste from food packaging. Styrofoam packaging was chosen because it can maintain hot/cold food temperature, comfortable to hold, maintain the freshness and integrity of packaged food, light, and inert against food acidity. Because of these advantages, styrofoam packaging is used to package ready-to-eat food, fresh food, and food that requires further processing. This directly causes the resulting styrofoam waste to increase. 
The existence of this waste creates a very alarming problem, where this type of plastic is very difficult to decompose in nature, so it can damage the environment. Meanwhile, sawdust is a cheap waste and easy to be found in Indonesia, especially in North Sumatra, which has advantages such as easily processed, high particle bond strength, good adhesion properties, and most importantly its biodegradation properties. ${ }^{1}$

Compatibility between styrofoam used food packaging as the matrix and sawdust as the filler is a very important factor in producing composites with superior properties. In this study, maleic anhydride (MA) as a compatibilizer was chosen because it was expected to be a link between sawdust that contains cellulose and sawdust that was thermoplastic. Moreover, the pretreatment of sawdust was also done to reduce the level of lignin from wood, which can increase the interface strength of the composite. ${ }^{2}$

Thermal properties and the biodegradation of styrofoam composites filled with modified sawdust were examined. The thermal properties of composite materials were important to be studied because they were related to the application and usage time of a material. This is because composite materials, mainly polymer-based, are widely used as construction materials, household appliances, transportation, and industries where thermal properties must be considered. Therefore, a study of the thermal properties of composite materials was carried out through analysis of aging treatment. In addition, the use of organic material as composite filler, in this case, sawdust can improve the biodegradation properties of composites (partly biodegradation). The biodegradation properties of the composite material that was going to be carried out was to determine the composite decomposition pattern both in the soil and open air.

Styrofoam is made from styrene monomers through suspension polymerisation at certain pressure and temperature, then heating was conducted to soften the resin and evaporate the rest of the blowing agent. Styrofoam is produced from a mixture of $90 \%-95 \%$ polystyrene and $5 \%-10 \%$ gas such as n-butane or n-pentane. Polystyrene is a type of plastic that is quite inert made from styrene monomers through the polymerisation process, but given its extensive use and dangerous constituent monomers, US has set the monomer content of styrene in styrofoam for packaging ranging from $0.5 \%$ to $1.0 \%$ for food packaging.

Styrofoam is widely used throughout the world for various purposes including thermal insulation, packaging, coffee cups, plates, food trays, manufacturing of car components, etc. Styrofoam has many benefits including its 
insulation quality, durability, and high strength. On the other hand, the presence of benzene in styrofoam makes it non-biodegradable, so the use of styrofoam can be a major environmental problem unless recycled. ${ }^{3}$

Sawdust is a waste from the wood industry that can pollute the environment if it is not used properly. Based on the data from the Badan Pusat Statistik Indonesia (Central Bureau of Statistics), in 2013 the total wood production in North Sumatra was $68,013 \mathrm{~m}^{3}$, most of which was used for the production of household furniture. ${ }^{4}$ With the large amount of wood production, the waste produced was also quite large, which was around $27,205 \mathrm{~m}^{3}$. Sawdust contains high cellulose content, which is equal to $72 \%$. In addition to cellulose, sawdust also contains $15 \%$ of hemicellulose contents and $30 \%$ of lignin contents. ${ }^{5}$

The use of natural fibre in the manufacture of composites was due to its cellulose content, which is very influential on the composite produced. Natural fibre consists mainly of cellulose, hemicellulose, pectin, and lignin. Cellulose is a semi-crystalline polysaccharide and is hydrophilic. Hemicellulose is an amorphous polysaccharide with a lower molecular weight compared to cellulose. The amorphous nature of hemicellulose in fibre makes the fibre partially soluble in water and alkaline solution. Pectin functions to unite the fibres containing polysaccharides such as cellulose and hemicellulose. Meanwhile, lignin is an amorphous polymer but unlike hemicellulose, lignin consists of aromatic compounds and has little effect on water absorption. The advantages of using cellulose fibres as fillers in composite polymers are environment friendly, high tensile strength and modulus, and relatively reactive surfaces. ${ }^{6}$

Natural fibres are used as reinforcing materials in polymer technology for the following reasons:

1. Natural fibres can be bound to each other because of the hydrogen bonds between cellulose molecules.

2. Has high flexural properties.

3. Has a large surface area so that the touch of the interface bond with the fibre and matrix is greater.

4. The use of natural fibres in the manufacture of composites is also influenced by costs, economic criteria, namely the factor of availability of raw materials in large quantities, and cheaper costs compared to synthetic fibres. 
According to Madhukiran et al., the use of natural fillers as composite filler materials has several advantages, namely: ${ }^{7}$

1. Environmentally friendly because of the biodegradability.

2. Has high strength and rigidity.

3. Renewable.

4. Has good thermal insulation properties.

5. Has high resistance to fractures.

On the other hand, natural fillers also have several advantages and disadvantages, namely:

1. Easily absorb water (absorption).

2. Has a low quality variation.

3. Has low thermal stability.

Many studies have been carried out that use natural fillers as reinforcements in composites, such as bagasse, banana and pineapple, oil palm, hemp, and coconut. ${ }^{7-11}$ However, the addition of biopolymers in plastic waste such as polyethylene has also been studied. ${ }^{12}$

\subsection{Maleic Anhydride (MA) as Compatibilizer}

MA is one of the compatibilizer materials that is often used in the preparation of composites. MA is an unsaturated vinyl compound, which is a raw material in the synthesis of polyester resins, rubber surface coatings, detergents, additives, and lubricating oils. The presence of the maleic group can increase molecular weight and its unsaturation properties make it easier to form a film with better adhesion (coherent). The maleic group can also improve the impact resistance, flexibility, and hardness of scratches better. Generally, MA is known to strengthen adhesion, which is the attractive force between non-similar molecules. Figure 1 shows the structure of MA.

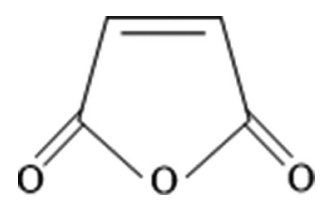

Figure 1: The structure of MA. 


\subsection{Material Thermal Properties}

Thermal properties of composite materials are important in the application and age of a product. Because most polymer materials, especially composites, are used in the field of construction, household appliances and industry, good material thermal resistance has become an important consideration. Information about the thermal properties of a composite material is important both in terms of the process and the final product. Most polymer materials are processed and fabricated at high temperature, until melted and then cooled to solid at room temperature. Sudden changes in temperature from relatively high to low are usually followed by shrinkage and changes in size. These effects must be considered during the process and will be increasingly complex for multiphase products such as composites. Therefore, the preparation of composite materials requires the study of the thermal properties of composite materials and thermal decomposition. ${ }^{9,10}$

\subsection{Biodegradation of Composite Materials}

The process of plastic degradation in the environment begins with the chemical decomposition stage, which results in low molecular weight polymers. The decrease in molecular weight is caused by the termination of the chain through the process of hydrolysis and oxidation. Hydrolysis occurs in the environment with or without the presence of an enzyme, whereas the oxidation process occurs because of the presence of oxygen and ultraviolet light. The next process is with microorganisms (bacteria, fungi, and algae) and enzyme activity (intercellular and extracellular). Examples of microorganisms include phototropic bacteria (rhodospirilium, rhodopseudomonas, chromatium, and thiocystis), endospores (bacillus and clostridium), gram-negative aerobes (pseudomonas, zogloa, and azotobacter rhizobium), actinomycetes, and alcaligenes. Some fungi can emit enzymes that can catalyse oxidation reactions from both cellulose and from lower molecular weight oligomers produced by enzymes in cellulose. ${ }^{13}$

\section{EXPERIMENTAL DETAILS}

\subsection{Preparation of Raw Materials and Delignification Process of Sawdust}

Styrofoam food packaging of polystyrene was collected and cleaned/ washed from the dirt and then dried and compacted by means of a bottle. Furthermore, styrofoam was cut into the size of $1 \times 1 \mathrm{~cm}$. Meanwhile, for sawdust filler, it was obtained from refining sawdust using a blender to obtain a mesh size of 100 . Sawdust was delignified with $500 \mathrm{~mL} 2 \% \mathrm{NaOH}$ solution at $80^{\circ} \mathrm{C}$ for $2 \mathrm{~h}$. 
The sawdust was filtered, and the pulp was washed with distilled water until the filtrate was neutral. A $\alpha$-cellulose purification was carried out from a sample by using $500 \mathrm{~mL}$ of $17.5 \% \mathrm{NaOH}$ solution at $80^{\circ} \mathrm{C}$ for $0.5 \mathrm{~h}$. It was filtered and the pulp was washed with distilled water to neutral filtrate. Bleaching was carried out with $\mathrm{H}_{2} \mathrm{O}_{2}$ at $60^{\circ} \mathrm{C}$ for $1 \mathrm{~h}$. Bleached sawdust was filtered and washed with distilled water and then dried in the oven at $60^{\circ} \mathrm{C}$ for $1 \mathrm{~h}$. The mesh size of sawdust was 100.

\subsection{Blending and Moulding of Composite}

Styrofoam was dissolved with chloroform then sawdust and MA were put into the solution and mixed manually. The mesh size of the powder used was 100 . The compositions of styrofoam and wood powder were $70 \%$ and $30 \%$, respectively. Meanwhile, the MA composition used was $6 \%$ of the total composite weight. After the composite was stirred and mixed, the mixture was put into the mould according to the test carried out and then pressed using a hot press machine (as shown in Figure 2) at $130^{\circ} \mathrm{C}$ for $10 \mathrm{~min}$.

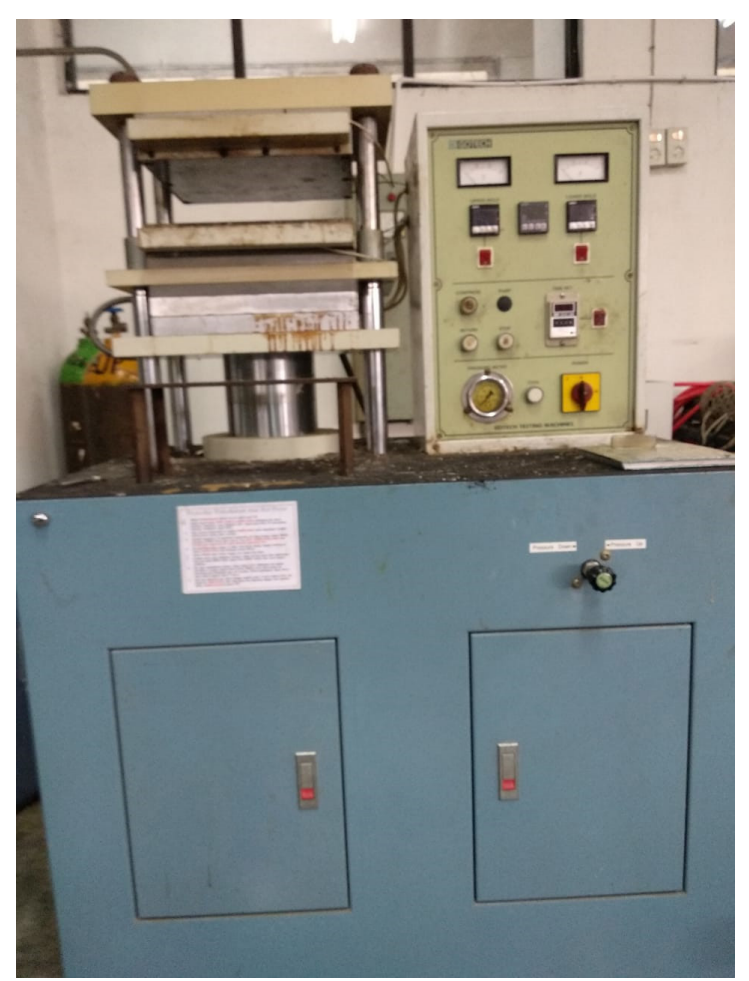

Figure 2: Hot press machine. 


\subsection{Aging Treatment}

Aging testing was done by placing the sample in the shape according to the physical test, tensile test, bending and impact test in the oven. Each sample was heated at $70^{\circ} \mathrm{C}$ for seven days. Furthermore, the samples were tested for mechanical properties. In samples that experienced aging treatment, after mechanical testing, the retention percentage of the mechanical test values were calculated using Equation 1.

$$
\text { Retention \% }=\left(\frac{W_{1}}{W_{0}}\right) \times 100 \%
$$

where, $W_{1}=$ test value after aging and, $W_{0}=$ original test value.

\subsection{Testing of Composites}

\subsubsection{Tensile test according to ASTM D-638 type IV}

Mechanical properties are usually studied by observing the tensile strength and elongation of materials using the AI700 tensiometer at the research lab in Faculty of Engineering, Universitas Sumatera Utara.

\subsubsection{Flexural strength test according to ASTM D-790}

The specimens to be tested for flexural strength had a slab shape and the testing was done with a three-point bend test using an instron machine.

\subsubsection{Impact strength test according to ASTM D 4812-11} method..$^{14}$

Specimens tested for impact strength followed the Unnotched Izod

\subsubsection{Composite biodegradation rate test}

The biodegradation rate test was carried out on composite with the size of $2 \times 5 \times 5 \mathrm{~cm}$ in two ways, i.e. burying in soil (landfill) and hanging in open air. Both methods were carried out for four months (125 days) with observation done every 15 days. The composite biodegradation rate was observed based on weight reduction during the composite hanging and burying process. 


\section{RESULTS AND DISCUSSION}

\subsection{Effect of Aging Treatment on Composite Retention Percentage}

Table 1 shows the retention percentage of composite materials for each composite property tested.

Table 1: Percentage of composite retention before and after aging treatment.

\begin{tabular}{lccc}
\hline Composite properties & Before aging & After aging & Retention \% \\
\hline Tensile strength $(\mathrm{MPa})$ & 33 & 23 & 70 \\
Elongation at break $(\%)$ & 7.5 & 4.0 & 52.8 \\
Young modulus $(\mathrm{MPa})$ & 950 & 200 & 21 \\
Flexural strength $(\mathrm{MPa})$ & 15.8 & 7.0 & 44.3 \\
Impact strength $\left(\mathrm{J} \mathrm{cm}^{-2}\right)$ & 300.0 & 125.0 & 41.7 \\
\hline
\end{tabular}

From Table 1, it can be seen that the retention percentage of tensile strength is above $50 \%$, this shows that the interaction between fillers and matrix is relatively good so that the use of MA as a compatibilizer material gives a positive result. As is well known, tensile test is closely related to the interface surface of matrix and filler. If the interaction that occurred was quite optimal, the aging treatment performed on the composite does not significantly affect the tensile strength of the material. For elongation at break, the results (as shown in Table 1) also indicate that the causal factor for the low elongation at break value is the longterm heating process that has damaged the molecular network in the composite.

Table 1 also shows a decline in Young's modulus after the composite has experienced aging treatment. The retention of $21 \%$ indicates that the provision of heat for a long time has damaged the structure of composite components.

It can be seen that the retention percentage of composite flexural strength is relatively low, i.e. below $50 \%$ (as shown in Table 1 ). The low composite retention percentage is also related to the termination of the chain in the composite structure so that when the flexural test was carried out, the transfer of force between phases did not take place optimally. This termination of chain also reduced the molecular weight of composite components. 
For impact strength, the composite retention percentage decreased to below $50 \%$. This shows that the main factor causing the decrease in composite impact strength is the degradation experienced by the composite component materials during the aging treatment. The low retention percentage value also shows that when the impact test was carried out, both the matrix (styrofoam) and filler (sawdust) underwent the chain termination together, so that the power transfer did not take place optimally.

\subsection{Biodegradation of Styrofoam Composites Filled with Sawdust Treated with Hanging in the Open Air and Burying in the Soil}

Figure 3 shows the relationship between the hanging time of composite in the open air and the time of burying in the soil against the percentage of reduction. On the curve, it can be seen that the percentage of composite weight reduction is below $0.3 \%$. This shows that the addition of sawdust filler in styrofoam filler has a relatively small effect on the material to the degradation process. The percentage of weight reduction increases with increasing time both for samples that were hung in the open air and those buried in the ground. The weight reduction that occurred came from the decay of sawdust filler, which has been decomposed by microorganisms. As for styrofoam, due to its structure, it was very difficult to decompose.

For composites buried in the soil, the first 45 days showed the percentage of weight reduction had a negative value, which means that there was an increase in the weight of the material in the first 45 days. This might be caused by the absorption of water by the material in the soil so that it adds to the weight of the composite. As time goes on, the composite then loses greater weight until day-125. This occurs because the sawdust has been decomposed by microorganisms in the soil. Cellulose was broken down by cellulase enzymes. With the attack of microorganisms, the material decomposed and damaged the structure of the material. ${ }^{13}$

Meanwhile, the percentage of the weight reduction of composites hung in the open air indicates that the composite has only a slight increase in weight on the 45th day. This was caused by composites containing sawdust, which in the initial stage absorbed water in the air. Furthermore, composites lose weight, which was greater with increasing time until day- 125 . 


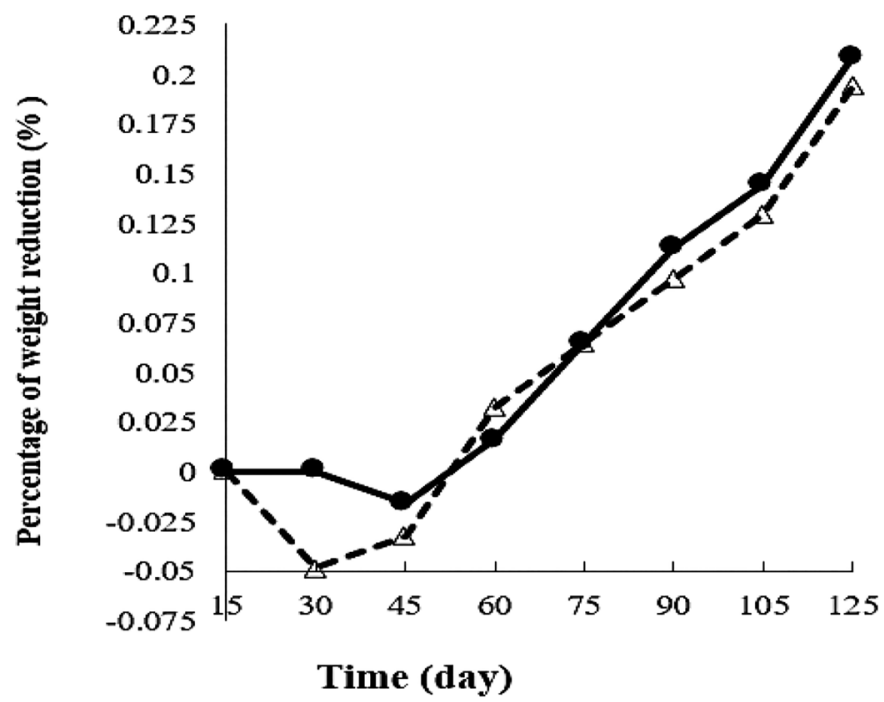

$\longrightarrow$ Composite hanging in the open air

$-\Delta-$ Composite burying in the soil

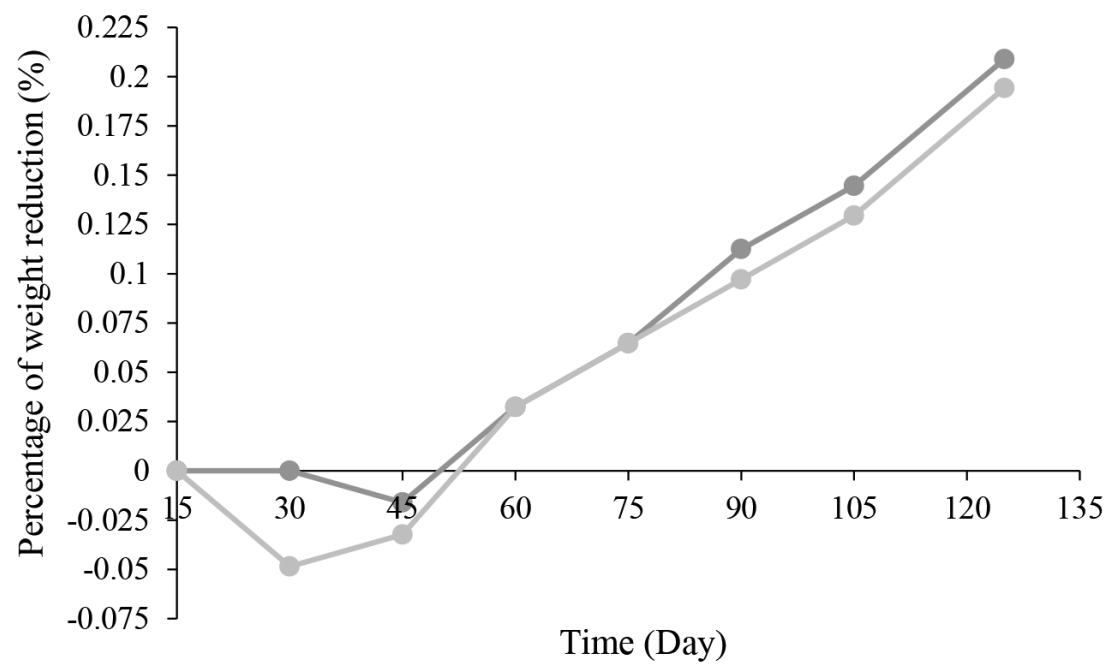

- Composite hanging in the open air - Composite burying in the soil

Figure 3: Effect of biodegradation treatment and processing time on the percentage of composite weight reduction. 
The picture of surface morphology of composites that have been degraded in soil can be seen in Figure 4. Surface morphology shows broken surface, which contains many holes originating from sawdust that has been degraded in the soil for 125 days.

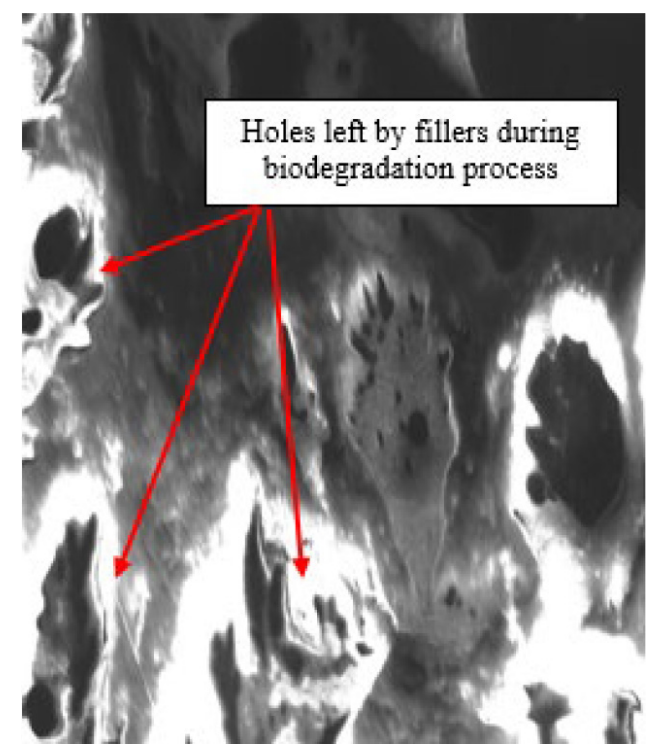

Figure 4: The surface morphology of the resulting degradation in the soil after 125 days (mag. 200×).

The percentage of weight reduction of composites hung in the open air tends to be greater than those buried in the soil as shown in Figure 5. The first step in the process of decomposing materials in the open air is the termination of main chain to form parts that have low molecular weight (oligomers) that can be assimilated by microbes. Decreasing molecular weight was caused by chain termination through hydrolysis and oxidation processes. Hydrolysis occurred in the environment with or without the presence of an enzyme. Some fungi can emit enzymes that can catalyse oxidation reactions both from sawdust and from oligomers that have lower molecular weight produced by enzymes in sawdust. In this case heat can also cause the hydrolysis process, while oxidative termination occurred due to the presence of oxygen and ultraviolet light. ${ }^{6,13}$ 


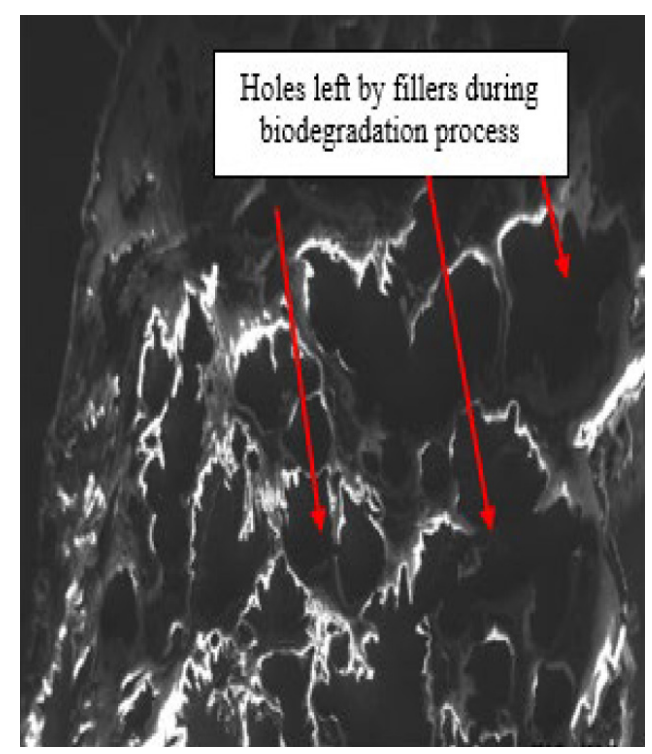

Figure 5: The surface morphology of the resulting degradation in the open air after 125 days (mag. 200×).

\section{CONCLUSION}

Aging treatment was carried out to test the thermal resistance of styrofoam composite materials filled with modified sawdust. The results obtained showed that the mechanical properties of composites such as tensile strength, bending and material impact decreased after aging treatment. The retention percentage of mechanical properties was also low indicating that the composite has undergone thermal degradation during the aging treatment. For biodegradation properties, the degradation rate was very low and if viewed from the test treatment, composites hung in the open air were more easily degraded than those buried in the soil.

\section{ACKNOWLEDGEMENTS}

The authors gratefully acknowledge that the present research was supported by the Directorate of Research and Community Service, Director General of Strengthening Research and Development, Ministry of Research and Technology, and Ministry of Higher Education of the Republic of Indonesia through the grant for year 2019. 


\section{REFERENCES}

1. Idrus, M. A. M. M., Sinin, H., Muhammad, R. R. \& Muhammad, S. I. (2011). Treated tropical wood sawdust-polypropylene polymer composite: Mechanical and morphological study. J. Biomater. Nanobiotechnol., 2(4), 435-444, https://doi.org/10.4236/jbnb.2011.24053.

2. Zaaba, N. F., Jaafar, M. \& Ismail, H. (2017). The effect of alkaline peroxide pretreatment on properties of peanut shell powder filled recycled polypropylene composites. J. Engi. Sci., 13, 75-87, https://doi.org/10.21315/jes2017.13.6.

3. Demirkir, C., Semra, C. \& Ismail, A. (2013). Some technological properties of wood-styrofoam composite panels. Compos. Part B-Eng., 55, 513-517, https://doi.org/10.1016/j.compositesb.2013.07.024.

4. Badan Pusat Statistik Indonesia. (2014). Kehutanan. Jakarta: Badan Pusat Statistik Indonesia. Retrieved from http://www.bps.go.id. on 5 July 2019.

5. Saifuddin, M. I., Bambang, E. \& Khairul, F. (2011). Pengaruh penambahan campuran serbuk kayu terhadap kuat tekan Beton. e-Journal Mahasiswa Teknik, 1(1).

6. Panaitescu, D. M., Frone, A. N., Ghiurea, M., Spataru, C. I., Radovici, C. \& Iorga, M. D. (2011). Properties of polymer composites with cellulose microfibrils. In B. Attaf (ed.), Advances in composite materials: Ecodesign and analysis. Rijeka, Croatia: InTech, 103-122, https://doi.org/10.5772/14682.

7. Madhukiran, J., Srinivasa, R. \& Madhusudan. (2013). Fabrication and testing of natural fiber reinforced hybrid composites banana/pineapple. Int. J. Mod. Eng. Res., 3(4), 2239-2243.

8. Zizumbo, A., Angel, L. C., Eder, L. M., Edgar, G. H., Domingo, M. \& Roberto, Z. (2011). Polystyrene composites prepared with polystyrene grafted-fibers of sugarcane bagasse as reinforcing material. J. Mex. Chem. Soc, 55(1), 33-41.

9. Ewulonu, C. M. \& Isaac, O. I. (2011-2012). Properties of oil palm empty fruit bunch fibre filled high density polyethylene. Int. J. Eng. Technol., 3(6), 458-471.

10. Gon, D., Kousik, D., Palash, P. \& Subhankar M. J. (2012). Composites as wood substitute. Int. J. Text. Sci., 1(6), 84-93, https://doi.org/10.5923/j. textile.20120106.05.

11. Hussain, S. A., Pandurangadu, V. \& Palanikumar, K. (2011). Mechanical properties of green coconut fiber reinforced HDPE polymer composite. Int. J. Eng. Sci. Technol., 3(11), 7942-7952.

12. Husseinsyah, S., Azmin, A. N. \& Suppiah, K. (2016). Effect of eco-degradant on properties of recycled polyethylene (RPE)/chitosan biocomposites. J. Eng. Sci., $12,53-64$.

13. Zheng, Y. \& Yanful, E. K. (2005). A review of plastic waste degradation. Crit. Rev. Biotechnol., 25(4), 243-250, https://doi.org/10.1080/07388550500346359.

14. Slavin, S. E. \& Beswick, G. T. (1993). Instrumented izod impact testing. J. Appl. Polym. Sci., 49(6), 1065-1070, https://doi.org/10.1002/app.1993.070490613. 